\title{
UNDERWATER PHOTOGRAMMETRY AND 3D RECONSTRUCTION OF MARBLE CARGOS SHIPWRECK
}

\author{
C. Ballettia , C. Beltrame ${ }^{b}$, E. Costa ${ }^{a}$, F. Guerra ${ }^{a}$, P. Vernier ${ }^{a}$ \\ ${ }^{a}$ Università Iuav di Venezia, S. Croce 191, 30135 Venezia, Italy - (balletti, ecosta, guerra2, vernier)@iuav.it) \\ b Università Ca Foscari Venezia, Dorsoduro 3484/D, 30123 Venezia, Italy - beltrame@unive.it
}

\section{Commission V}

KEY WORDS: Cultural Heritage, Maritime archaeology, Underwater Survey, Multi-image photogrammetry, 3D modelling, GPS

\begin{abstract}
:
Nowadays archaeological and architectural surveys are based on the acquisition and processing of point clouds, allowing a high metric precision, essential prerequisite for a good documentation. Digital image processing and laser scanner have changed the archaeological survey campaign, from manual and direct survey to a digital one and, actually, multi-image photogrammetry is a good solution for the underwater archaeology. This technical documentation cannot operate alone, but it has to be supported by a topographical survey to georeference all the finds in the same reference system. In the last years the Ca' Foscari and IUAV University of Venice are conducting a research on integrated survey techniques to support underwater metric documentation. The paper will explain all the phases regarding the survey's design, images acquisition, topographic measure and the data processing of two Roman shipwrecks in south Sicily. The cargos of the shipwrecks are composed by huge marble blocks, but they are different for morphological characteristic of the sites, for the depth and for their distribution on the seabed. Photogrammetrical and topographical surveys were organized in two distinct methods, especially for the second one, due to the depth that have allowed an experimentation of GPS RTK's measurements on one shipwreck. Moreover, this kind of three-dimensional documentation is useful for educational and dissemination aspect, for the ease of understanding by wide public.
\end{abstract}

\section{INTRODUCTION}

Photogrammetry has long been an efficient technique in documenting underwater archaeology: it was used since 196070's with the first stereo-pairs cameras, adapting the aerial surveying method to underwater conditions (Bass, 1966, Hohle, 1971, Leatherdale et al.,1991, Capra, 1992). Pros and cons are evident: the approach minimized the time required and offered high accuracy in recording, measuring and interpreting photographic images, but it imposed some operating constrains, such as parallel optical axes in accordance with required stereovision conditions. Therefore a high degree of technical knowledge, specialist unwieldy equipment, such as a double camera mounted on a metal structure, extensive manual processing were required to produce relatively few measurements.

Over the last few years, the necessity to produce detailed and accurate three-dimensional mapping, combined with cheapness, quickness and ease in execution led to apply image-based techniques and digital photogrammetry to underwater archaeological site documentation (Green et al. 2002, Canciani et al 2003, Bass, 2006, Green, 2004, Drap et al, 2007). Many trial experiences in underwater features 3D modelling are now realized using consumer cameras and processing data with special software in very automated ways (McCarthy et al., 2014). This approach to calibration and measurement is recognized as a powerful and accessible tool for no-destructive archaeology all around the world (Drap et al., 2013): for instance, the possibility to check, on the field, the results of the matching features process is surely one of the main advantages. In the last years, Ca' Foscari University and University IUAV of Venice are conducting a research on the application of integrated techniques to support underwater metric documentation. The lesson learned and confirmed by recently published papers (Menna et al., 2011, Skarlatos et al., 2012,
Eric et al., 2013; Henderson et al, 2013; Demesticha et al., 2014) shows how multi-image photogrammetry is, at the moment, a capable technique for mapping and retrieving the shape and geometry of objects completely submerged. It has transformed underwater photogrammetry from a highly technical and costly process to a much more powerful and accessible tool (McCarthy et al., 2014).

This paper describes the workflow regarding the survey's design, images acquisition, topographic measure and the data processing to obtain $2 \mathrm{D}$ and $3 \mathrm{D}$ final representation realized by the authors in two underwater Sicilian sites in May and September 2014.

The presented experience want to highlights the method's importance both from a metric and a recording point of view, because the production of dense and accurate $3 \mathrm{D}$ model offers many opportunities for interpretation and presentation of underwater archaeological sites. It is not only a very realistic documentation, that is a "high fidelity" model, but also a recording which can be "consulted" to take precise measures. This, indeed, allows in every moment to virtually "return" to the site, also if it is difficult to access, to verify many kinds of data: measures, shapes, colours, locations etc. 3D has also the potential to allow the public to experience underwater archaeological sites "in dry suites" (Costa, Beltrame, Guerra, in press).

\section{THE ARCHAEOLOGICAL CONTEXT}

\subsection{Case studies}

In 2014 the department of Studi Umanistici of Ca' Foscari University, coordinated by the maritime archaeologist Carlo Beltrame, in collaboration with Circe Laboratory of Photogrammetry of IUAV University of Architecture of Venice, coordinated by Francesco Guerra, and the Soprintendenza del 
Mare of the Regione Sicilia, has investigated two shipwrecks of cargos of marble blocks dated at the Roman age.

The integrated survey realized on these shipwrecks, which are different for morphological characteristic of the sites, develops in these phases:

- cleaning of the subject from sand and vegetation;

- manual tape measurements and detail photographs of the archaeological sites;

- laying of markers (CGP) on the upper surfaces of the marble blocks;

- images acquisition for multi-image digital photogrammetry;

- topographic survey of the CGP, with trilateration (Direct Survey Method) and GPS RTK's measurement; - 3D reconstruction.

\subsection{Marzamemi}

The first shipwreck, near Marzamemi (Siracusa) in southeast Sicily, was discovered in 1958 by fishermen and in 1959 was documented with a first survey and some photographs by G. Kapitaen and P.N. Gargallo. G. Kapitaen dated the site at 3rd century A.D., according to the study of two types on amphorae (Kapitaen, 1961).

Actually, the site is composed by 14 white marble blocks, positioned scattered on the seabed; the surfaces of the blocks are irregular and degraded, but it is possible to recognize big columns and squared blocks.

The principal cluster is composed by 9 semi-finished item:

- 3 big columns, with a maximum length of $595 \mathrm{~cm}$ and a diameter of $138 \mathrm{~cm}$ (figure 1);

- 3 big squared blocks, the biggest measures 215 x $168 \times 114$ (h) cm (figure 2);

- 1 big irregular block, with a maximum length of $343 \mathrm{~cm}$;

- 3 little parallelepiped blocks.

The other four blocks are far from the main cluster:

- $15 \mathrm{~m}$ south there is the biggest column of the site and also the biggest column found underwater in the Mediterranean. It measures $640 \times 185 \mathrm{~cm}$ and it weighs 49 tons;

- $15 \mathrm{~m}$ south-west there are 2 medium blocks overlapping between them;

$-32 \mathrm{~m}$ west there is another column.

The total tonnage, calculated on a specific gravity of 2,68 gr, is 164 tons, with a total volume of $61 \mathrm{~m}^{3}$.

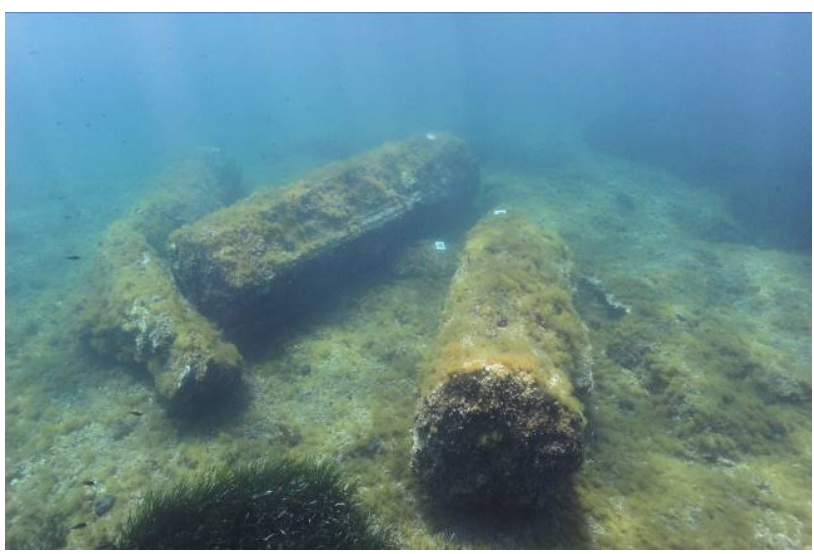

Figure 1. Marzamemi shipwreck. Detail of the columns. (photo: D. Della Libera)

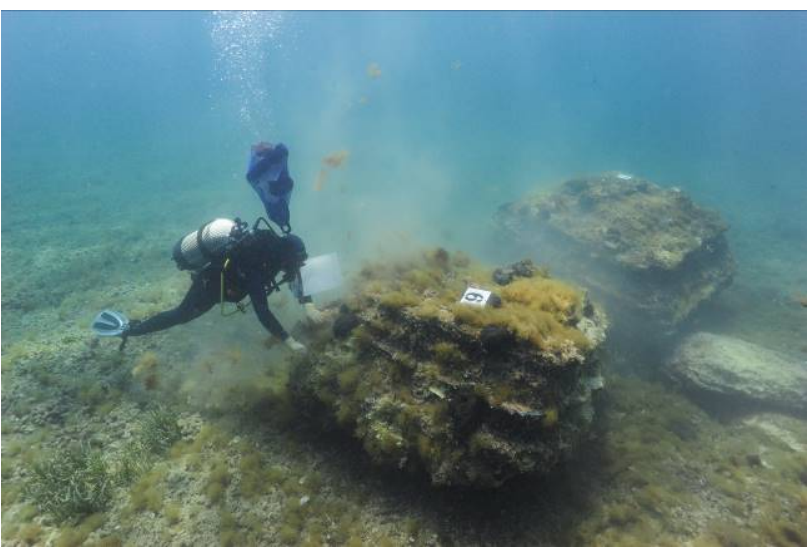

Figure 2. Marzamemi shipwreck. Detail of the squared blocks. (photo: D. Della Libera)

\subsection{Cape Granitola}

The second shipwreck, near Granitola (Mazara del ValloTrapani) in south-west Sicily, was documented with a first survey in 1976 by G. Purpura (Purpura, 1977) and then by Poseidon private company which made a simple bi-dimensional plan. The shipwreck is dated in the 3rd century A.D.

The shipwreck lies at $3 \mathrm{~m}$ under the sea level and it is only 200 $\mathrm{m}$ off the shore; it is represented by an homogeneous cargo of 63 squared marble blocks and 2 (or perhaps 3) podia, found in stowage position, on parallel lines (figure 3-4).

The marble blocks are corroded and concretionated but are cut squared in various dimensions, with length from 60 to $330 \mathrm{~cm}$.

Some of them are broken but the coherent position gives the possibility to virtually re-gather them.

We made a rapid calculation of the tonnage, realized on the maximum measure (length, width and high) of the visible blocks and the tonnage is about 150 tons. This consideration could be validated only after the excavation of all site, because some of the block are even now hide by the seaweeds.

Archaeometric analysis made by Lorenzo Lazzarini (LAMA, University IUAV of Venice) on only few samples have preliminary proposed proconnesion marble, from Marmara Sea.

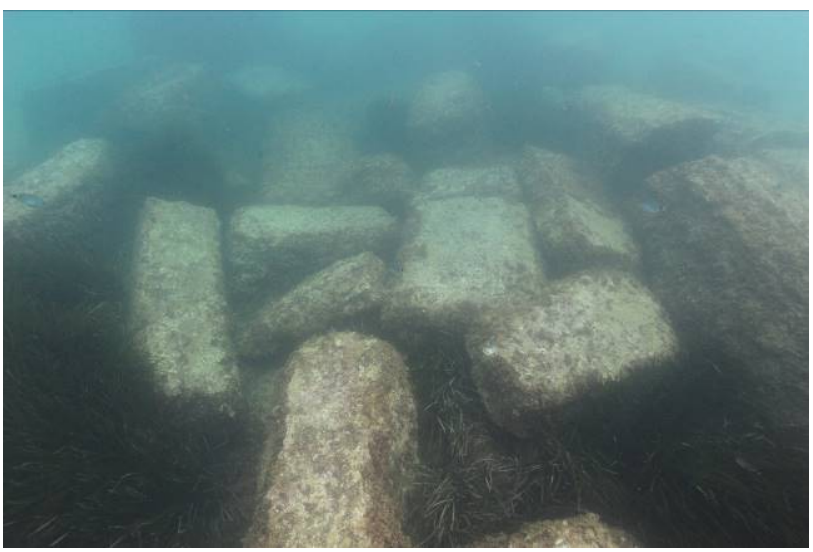

Figure 3. Cape Granitola shipwreck. (photo: D. Della Libera) 


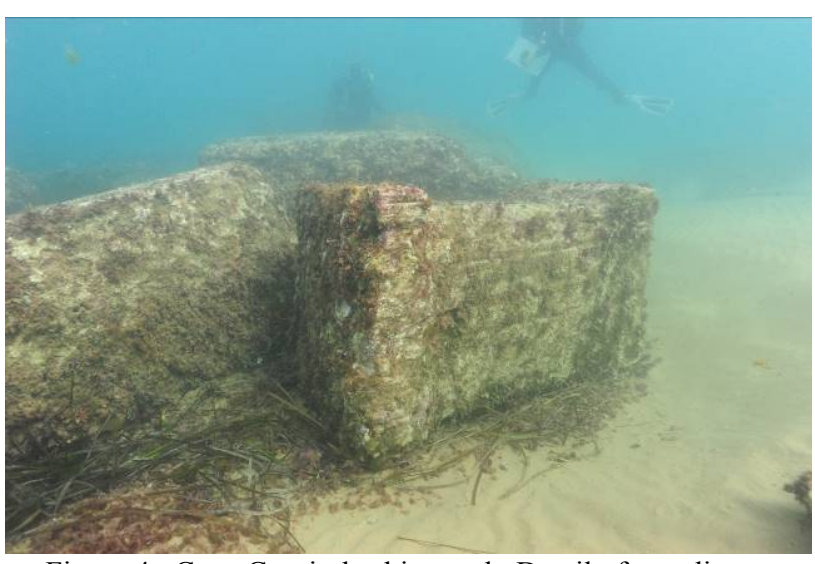

Figure 4. Cape Granitola shipwreck. Detail of a podium. (photo: D. Della Libera)

\section{PHOTOGRAMMETRIC TECHNIQUES AND TOPOGRAPHICAL SURVEY}

In the last few years interesting software and hardware solutions were proposed in order to reduce the costs of instruments (i.e. low cost consumer digital cameras), times in acquisition and processing without requiring trained personnel.

The image-based techniques, using algorithms derived from Computer Vision, such as the well known Structure from Motion and Dense Multi View 3D Reconstruction (Remondino et al. 2012), are able to automatically perform the whole pipeline reducing time both of images orientation and 3D reconstruction (Balletti et al., 2015).

Nowadays we can work with a wide variety of multi-image photogrammetry software, such as Photomodeler, Agisoft Lens, iWitness, MicMac, 3DF Zephir, etc. (Remondino, 2012), that can automatically perform camera self-calibration and offer the possibility to use several cameras and sensors to obtain dense point clouds or 3D models suitable for different fields of application.

These instruments are widely used for 3D reconstructions of monuments, for the rigorous modelling of lands, cities or archaeological sites and underwater finds, by creating complex models. This complexity depends from both the high number of acquired and elaborated data (images) and the articulation of the documented shapes.

A photogrammetric strip was realized by Duilio Della Libera for each shipwreck, as in aerial photogrammetry, taking care to obtain complete coverage with overlapping of the archaeological site. Usually, during the acquisition phase of the images, some external factors can create problems in producing the 3D survey: the variability of the light conditions, the turbidity of the water and the loss of colour with the increase of depth. Those elements can alter the texture information legible at the same point on an artefact; these conditions are overtaken with white balance or post-processing colour correction.

All the images - acquired, for the above-mentioned reasons, at the same dive - were aligned with Photoscan software, realizing a singlewide photogrammetric block. The system can offer precise measurement, but its accuracy is always related to the camera calibration.

In order to improve accuracy, the camera intrinsic parameters were preliminary calculated, because a simulation of the diving was previously done.

The calibration process was conducted entirely automatically in AgiSoft Lens, using some sets of photos of two checkerboards positioned on the bottom of a pool where the simulation was held. The estimated interior camera parameters (horizontal and vertical focal lengths, the coordinates of the principal point, the radial and tangential lens distortions in the Brown's model and the skew coefficient) were used later as initial parameters in Agisoft alignment process to better perform the system convergence.

As is well known, simulation can improve the data accuracy, but in the underwater calibration process, because the presence of one more media (water, air and glass) cannot use a simple function of the distortion as for standard calibration (Lavest et al., 2003). Moreover, the effect of refraction (depending on a number of parameters such as depth, temperature and salinity) can cause unstable modelling effects, so the intrinsic parameters of a submerged camera change significantly in comparison to the primary values.

There are other changes that should be taken into consideration during a preparation of a data acquisition plan: the Focal Length is larger and the Field of View is decreased underwater, thus a smaller area will be covered by a photograph then in the air; the turbidity of the water that drastically reduces the overall image contrast, hence the accuracy in image point marking

Photogrammetry was realized for each shipwreck in the same way as in aerial photogrammetry: in order to make spatial models, nadiral regular strips had to guarantee a complete coverage of the archaeological site with a suitable images footprint overlap, i.e. $60 \%$ between photos and at $20 \%$ between the strips (Drap, 2012).

For the two shipwrecks, we made two different photographic sets:

- on Marzamemi: zenital photographs, only on direction E-W and oblique photographs at $45^{\circ}$ and almost $90^{\circ}$ around the site, to take the details of the block. The dispersion of the 14 elements on the seabed gave the possibility to ring around them; - on Cape Granitola: nadiral photographs, on two directions N-S and E-W. The 65 blocks are close together and on a wide area, therefore a good system to take all the vertical side of the blocks is based on two directional series of photos. We made also oblique photos at $45^{\circ}$, but after computer processing these photos were removed, since the blue colour of the water column over the blocks created a blue points cloud on the surface of the block. Anyway, in this situation, nadiral photographs with a good overlap were enough to create the $3 \mathrm{D}$ model.

In our case studies, clear and shallow water, good light conditions and a high-quality white balance allowed a good chromatic result.

For the photographs, we used a single digital camera Nikon D 700 with a $20 \mathrm{~mm}$ lens hosted in an underwater housing with a hemispheric dome. Resolution of the photographs is highquality, 4256x2832 pixels, the ISO resolution at 1600 . Depending on the sets of images the F-stop is from 6.3 to 13 and the shutter from $1 / 250$ to $1 / 640 \mathrm{~s}$.

\subsection{Topographical survey}

In addition to the visual approach, photogrammetry has to be supported by a topographical survey (to acquire ground control points - GCP) to georeference all the finds in the same reference system.

The wrecks cargos are huge marble blocks, presenting differences in quantities, layout and depths, so the GCP's acquisition has two different solutions.

The blocks on the site of Marzamemi are scattered on the seabed, some of them far from the principal cluster; this kind of distribution implicates a subdivision of the photogrammetric survey in four different clusters, added, at a later stage, in the same reference system with a trilateration method. 


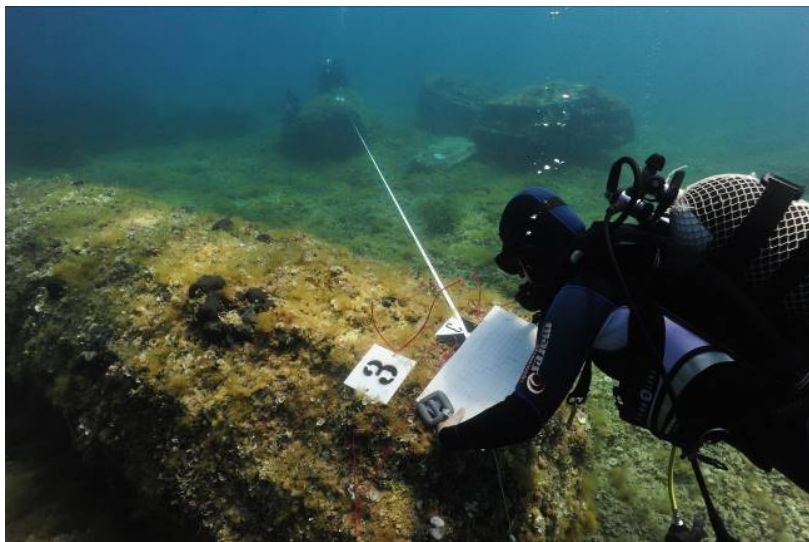

Figure 5. Marzamemi shipwreck. Trilateration of the CGP by DSM. (photo: D. Della Libera)

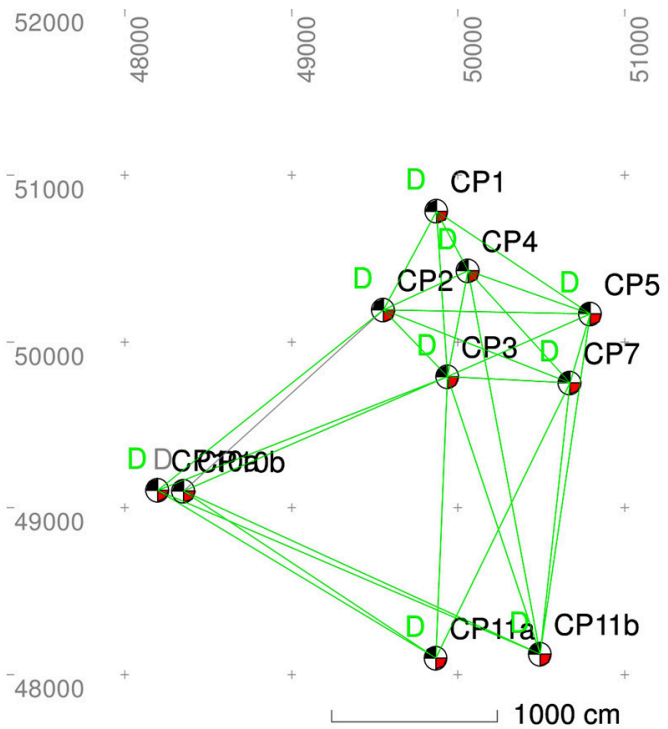

Figure 6. Processing of the measure took underwater of GCP by coordinates. Site Surveyor software.

The realized trilateration of numbered markers, placed on the upper side of some blocks, has been computed as a 3D topographic network using rigorous Least Squares techniques, following the DSM (Direct Survey Method) technique (Rule, 1989) (figure 5). The data were processed with Site Surveyor software to create $\mathrm{x}, \mathrm{y}, \mathrm{z}$ coordinate of the markers (figure 6). The coordinates are in a relative local system, which can be then georeferenced by GPS' survey in the world system.

The coordinates were inserted in Photoscan, in correspondence to the markers and they were employed both for roto-traslate the model in the right position and for check the position of the marker. The medium error resulted by the processing is 0,057 $\mathrm{m}$, which is tolerably low considering that the linear measure were taken with a measuring tape on variables distances from $4.30 \mathrm{~m}$ to $13 \mathrm{~m}$ for the main cluster and from $16.80 \mathrm{~m}$ to 35.45 for the three sets of blocks out of the principal site.

At Cape Granitola the depth of the shipwreck is about $3 \mathrm{~m}$ under the sea level. The markers applied on the blocks were surveyed by GPS RTK's measurements mounting the antenna on a $4 \mathrm{~m}$ pole (figure 7-8). The master station was positioned on an IGM trigonometric point. The dense points cloud coming from the photogrammetric block was referred to GPS GCP.

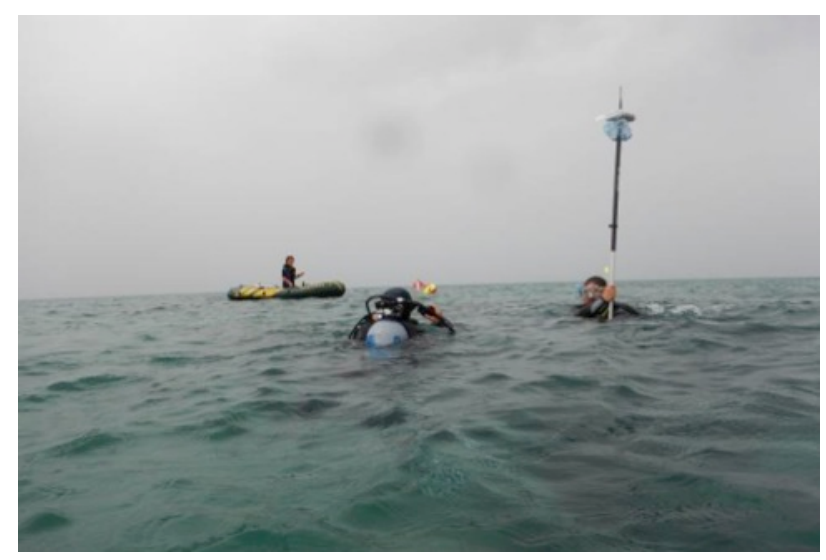

Figure 7. Cape Granitola shipwreck. Antenna of GPS RTK. (photo: D. Della Libera)

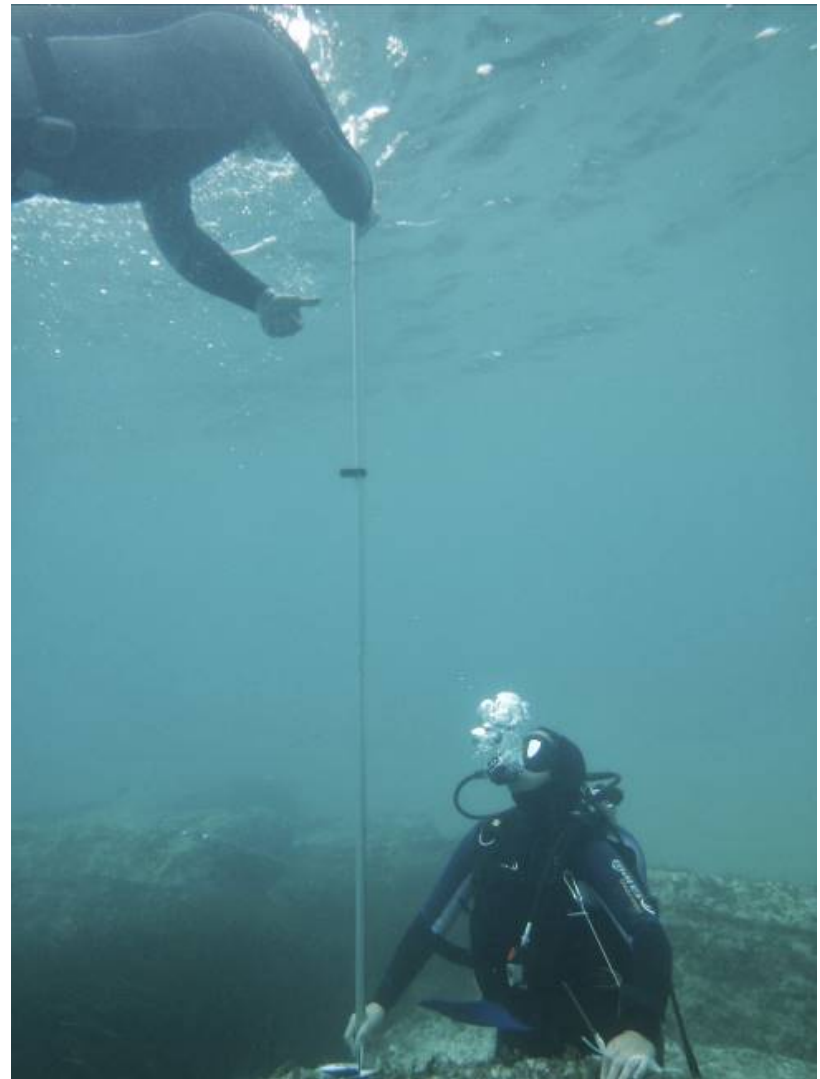

Figure 8. Cape Granitola shipwreck. Topographic measure of GCP. (photo: D. Della Libera)

Some CGP were not used in the absolute orientation phase, but later as checkpoints in order to evaluate the final accuracy.

\subsection{D reconstruction}

3D modelling and representation of the underwater sites are a new kind of documentation in the latest years, which is still in fast development. The photogrammetry of Marzamemi shipwreck, as mentioned above, is subdivided in four chunks of photographs, due to the disposition of the cargo: 495 images were used for the complete survey, 323 images of these only for the main cluster of blocks. In the case studies of Cape Granitola 
shipwreck, 918 images were loaded to AgiSoft PhotoScan.

"Align photos" command computed the camera positions and their orientation; the images were aligned with a high accuracy and, in comparison to ancient stereo-photogrammetry, this process is totally automated. As result, a sparse points cloud model was produced.

At a later stage, the software created a dense points clouds, to which triangulated meshes were applied. As a result of the survey, we have two 3D polygonal textured models of the sites, from which we have extrapolated some orthophotos from top viewpoint (figure 9) and some perspective views of the two shipwrecks (figure 10-11). The latest are useful for demonstration.

The textured model created by the software represents the marble blocks and the seabed; we have cleaned the model to highlight only the blocks, allowing direct elaborations on one single element, disconnected by the others.

The mesh of every single marble block was imported into a CAD program (figure 12) and it can be employed for further use, for different analyses and reconstructive hypothesis, opening new possibilities of documentation with both specialists and the wider public.

Here, the elements were measured and compared with the dimensions taken underwater during the archaeological campaign. The final 3D model is then realized by removing the irregularity of the mesh, due to the concretions and the presence of seaweed. A portion of the blocks, the part close and in contact with the seabed, was not visible during the images acquisition underwater and, consequently, on the model created by photogrammetry.

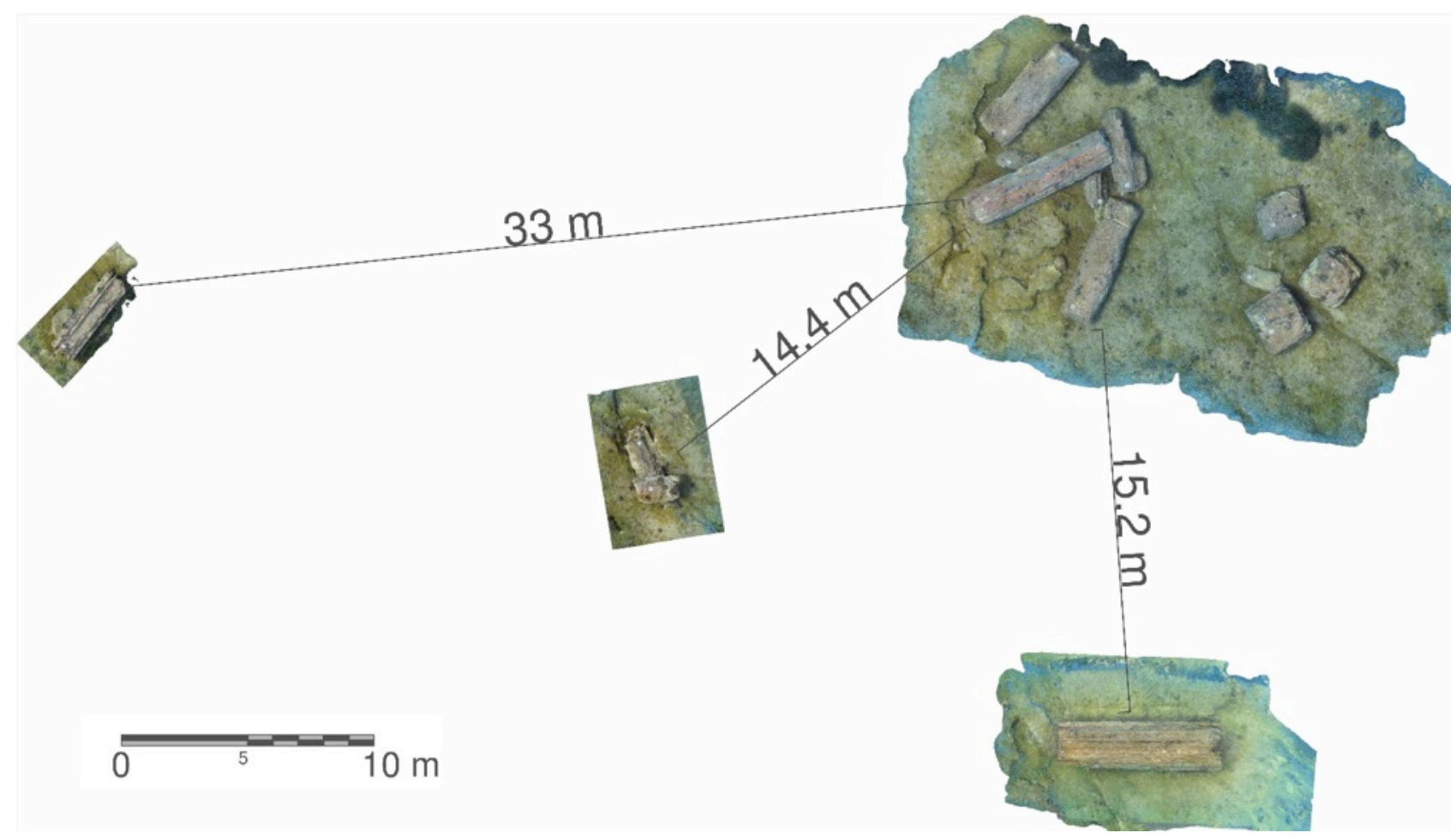

Figure 9. Orthophoto of Marzamemi shipwreck. Elaboration with Photoscan.

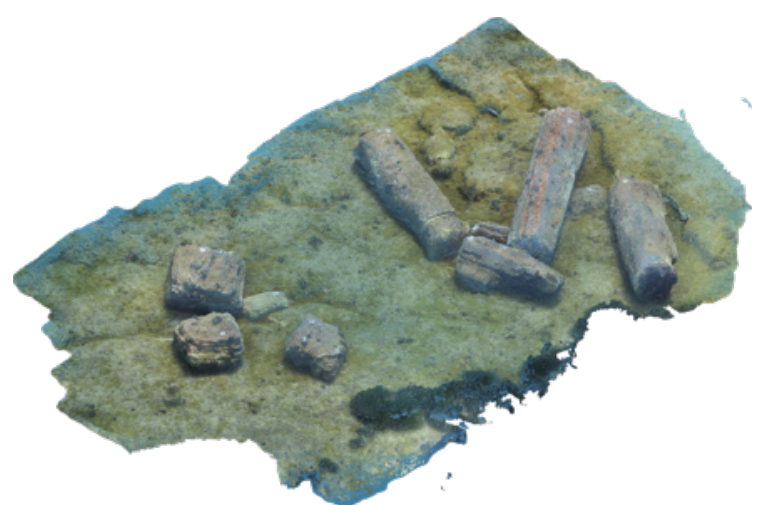

Figure 10. Marzamemi shipwreck. Elaboration with Photoscan.

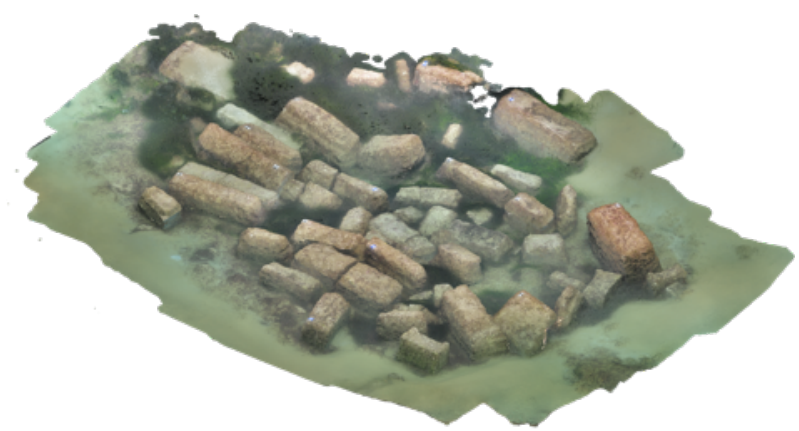

Figure 11. Cape Granitola shipwreck. Elaboration with Photoscan. 


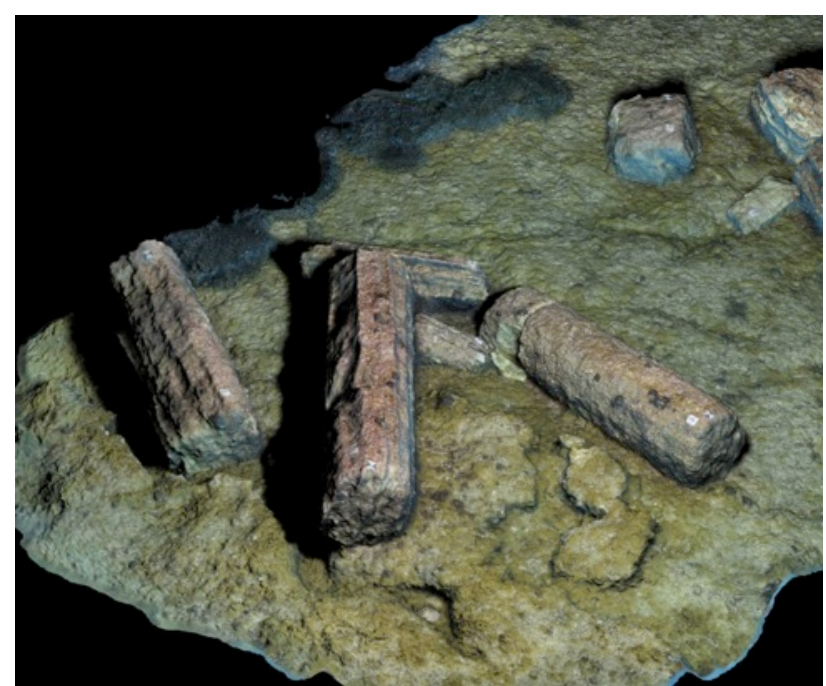

Figure 12. Mesh of the single blocks of Marzamemi shipwreck.

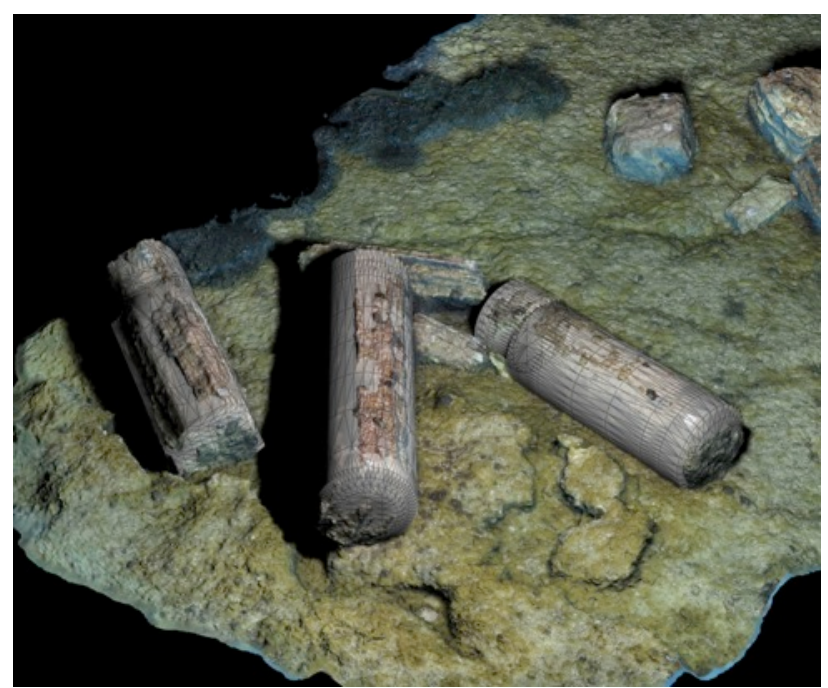

Figure 13. Marzamemi shipwreck. Model of the columns: ghosted view of polygonal reconstruction on the original mesh.

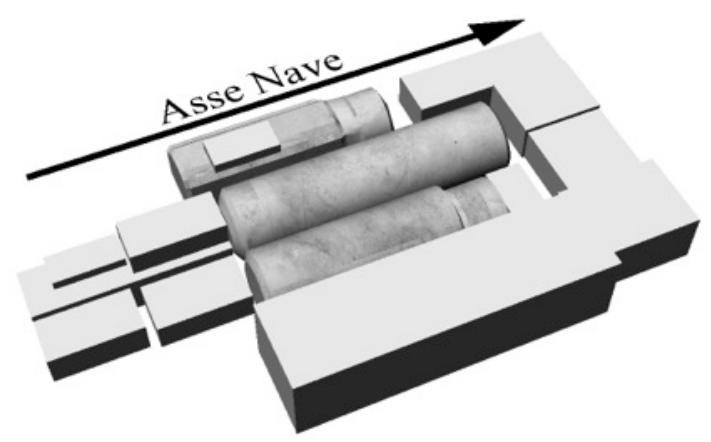

Figure 14. Marzamemi shipwreck. Reconstruction of the cargo in hypothetic stowage position. (Reconstruction: ing. S. Parizzi, E. Costa)

This part has been integrated on 3D CAD software to recreate the original shape of the blocks (figure 13).

Textures of the marble applied on the model were based on the type of the marble detected by isotope analysis.
The software has calculated also the precise volume both of every single item and of the entire cargo. Considering the specific gravity of the white marble and the volume, we have individuated the minimum tonnage of the cargos, on which it is possible hypothesize the reconstruction of the hull line of the two boat employed. The marble blocks were moved individually and rearranged on the correct position of stowage, based on hydrostatic calculations (figure 14).

\section{CONCLUSIONS}

This experience leads to make two different reflections: regarding survey, the results presented above show how new digital photogrammetric technologies have moved ahead underwater archaeology more quickly, just because multi-image photogrammetry is not only an inexpensive, rapid method for recording, but even easy and accurate in data acquisition and presents a largely automatic approach in processing.

From the perspective of representation, in addition to the capability of rendering the excavation by producing drawings or orthophotos and measuring 3D models, the management and exploration of digital models with stereoscopic display systems (such as virtual reality headset as Oculus) enable the possibility to explore deep underwater archaeological sites that can be inaccessible by not trained scuba divers. Virtual and augmented reality can offer to archaeologists new knowledge on data collected by accurate photogrammetric surveys concerning the finds identified on the site as well as the seabed itself, offering new and innovative ways to interact with these data.

\section{REFERENCES}

Balletti, C., Guerra, F., Scocca, V., and Gottardi, C., 2015, 3d integrated methodologies for the documentation and the virtual reconstruction of an archaeological site, Int. Arch. Photogramm. Remote Sens. Spatial Inf. Sci., XL-5/W4, 215-222, doi:10.5194/isprsarchives-XL-5-W4-215-2015, 2015.

Bass G.F., 1966, Archaeology under Water. London: Thames and Hudson

Bass G.F., 2006. New Techniques of Archaeology and Greek Shipwrecks of the Sixth and Fifth Centuries BC. PAPS 150:114

Canciani, M., Gambogi, P., Romano, F.G., Cannata, G. and Drap, P., 2003, Low Cost Digital Photogrammetry for Underwater Archaeological Site Survey And Artifact Insertion. The Case Study of the Dolia Wreck In Secche Della MeloriaLivorno-Italia. Int. Arch. Photogramm. Remote Sens. Spatial Inf. Sci., XXXIV- 5/W12, 95-100.

Capra, A., 1992. Non-conventional system in underwater photogrammetry. International Archives Photogrammetry and Remote Sensing, XXIX-B5, 234-240.

Costa, E., Beltrame, C., Guerra, F., in press, Potentialities of 3D reconstruction in Maritime Archaeology, in Computer Applications and Quantitative Methods in Archaeology (CAA) Paris 2014.

Demesticha, S., Skarlatos, D., Neophytou, A., 2014, The 4th century B.C. shipwreck at Mazotos, Cyprus: new techniques and methodologies in the 3D mapping of shipwreck excavations. Journal of Field Archaeology. 39.2, pp. 134-150. 
Drap, P., Seinturier, J.,Scaradozzi, D., Gambdogi, P., Long L., Gauch, F. 2007. Photogrammetry for virtual exploration of underwater archeolgical sites. Int. Arch. Photogramm. Remote Sens. Spatial Inf. Sci., XXXVI- 5/C53.

Drap, P., 2012, Underwater Photogrammetry for Archaeology. In Carneiro Da Silva, D. (ed), Special applications of photogrammetry. http://www.intechopen.com/books/specialapplications-of-photogrammetry/underwater-photogrammetryforarchaeology [Accessed: 15th March 2014].

Drap, P., Merad, D., Seinturier, J., Mahiddine, A., Peloso, D., Boi, J.-M., Long L., Chemisky, B., Garrabou, J., 2013, Underwater photogrammetry for archaeology and marine biology: 40 years of experience in Marseille, France. In Digital Heritage International Congress (DigitalHeritage), vol. 1, 28 oct -1 nov 2013, Marseille France.

Eric, M., Kovacic, R., Berginc, G., Pugelj, M., Stopinsek, Z., Solina, F., 2013, The impact of the latest 3D technologies on the documentation of underwater heritage sites. Proceedings of the 2013 Digital Heritage International Congress 2013, 28 Oct - 1 Nov, Marseille, France: IEEE, 2013, vol. 2.

Green J. 2004, Maritime Archaeology: a technical handbook, 2nd edn, London.

Green, J., S. Matthews, and T. Turanli. 2002. Underwater Archaeological Surveying Using PhotoModeler, VirtualMapper: Different Applications for Different Problems. IJNA 31:28392.

Henderson J., Pizarro O., Johnsons-Roberston M. and Mahon I., 2013, Mapping Submerged Archaeological Sites using StereoVision Photogrammetry, The International Journal of Nautical Archaeology, 42.2, 243-56.

Hohle, J., 1971, Reconstruction of the underwater object, in Photogrammetric engineering \& Remote sensing, PE\&RS Archives, September 1971, pp. 949-954.

Kapitaen, G., 1961, Schiffsfrachten antiker Baugesteine und Architekturteile vor den Kuesten Ostsiziliens, Klio 39, 276-318.

Leatherdale, J.D., Turner, D.J.,1991. Operation al experience in underwater photogrammetry. ISPRS Journal of photogrammetry and remote sensing. 46:104-112.

Lavest, J. M., Rives, G., Lapreste, J. T., 2003, Dry camera calibration for underwater applications, in Machine Vision and Applications, Vol.:13, pp.245-253.

McCarthy, J., Benjamin, J., 2014, Multi-image photogrammetry for underwater archaological site recording: an accessible, diver-based approach. Journal of maritime archaeology. 03/2014. Available from: http://www.researchgate.net/publication/260795817_Multi-

Image_Photogrammetry_for_Underwater_Archaeological_Site Recording_An_Accessible_Diver-Based_Approach. [Accessed: 1 st May 2014].

Menna F., Nocerino E., Del Pizzo S., Ackermann S., Scamardella A., 2011. Underwater photogrammetry for 3D modeling of floating objects: The case study of a 19-foot motor boat. In Sustainable Maritime Transportation and Exploitation of Sea Resources. Rizzuto E., Guedes Soares C. (edit). Crc Press, 537-544
Purpura, G, 1977, Un relitto con un carico di marmo a Capo Granitola (Mazara), Sicilia Archeologica, anno X, n. 33, Trapani: EPT.

Remondino, F., Del Pizzo, S., Kersten, P.T., Troisi, S., 2012. Low-cost and open-source solutions for automate image orientation-a critical overview. Lect. Notes Comput. Sci. 7616:40-54.

Rule, N., 1989, The Direct Survey Method (DSM) of underwater survey, and its application underwater, IJNA, 18.2, $157-162$.

Skarlatos, D., Demestiha, S., Kiparissi, S., 2012, An "open" methods for 3D modeling and mapping underwater archaeological sites. International Journal of Heritage in the digital era. Vol. 1, no. 1, March 2012. DOI: 10.1260/20474970.1.1.1. Available from: http://multiscience.metapress.com/content/q603163q0k861431/. [Accessed: 17th April 2014] 